\begin{tabular}{|c|c|}
\hline Title & Influence of the Porous Structure of the Cathode on the Discharge Capacity of Lithium-A ir Batteries \\
\hline Author(s) & Sakai, Kazuki; Iwamura, Shinichiroh; Mukai, Shin R. \\
\hline Citation & $\begin{array}{l}\text { Journal of the electrochemical society, 164(13), A 3075-A } 3080 \\
\text { https://doi.org/10.1149/2.0791713jes }\end{array}$ \\
\hline Issue Date & $2018-02-02$ \\
\hline Doc URL & http://hdl.handle.net/2115/68268 \\
\hline Rights & $\begin{array}{l}\text { (C) The Electrochemical Society, Inc. 2017. A II rights reserved. Except as provided under U.S. copyright law, this work } \\
\text { may not be reproduced, resold, distributed, or modified without the express permission of The Electrochemical Society } \\
\text { (ECS). The archival version of this work was published in Journal of the electrochemical society, volume 164, I ssue 13, } \\
\text { pp. A 3075-A 3080, 2017. }\end{array}$ \\
\hline Type & article (author version) \\
\hline Additional Information & There are other files related to this item in HUSCAP. Check the above URL. \\
\hline File Information & Supporting information.pdf \\
\hline
\end{tabular}

Instructions for use 
Supporting Information

\section{Influence of the porous structure of the cathode on the discharge capacity of Lithium-Air batteries}

Kazuki Sakai, Shinichiroh Iwamura*, Shin R. Mukai*

Graduate School of Engineering, Hokkaido University

N13W8, Kita-ku, Sapporo 060-6828, Japan

${ }^{*}$ Corresponding author. N13W8, Kita-ku, Sapporo 060-6828, Japan

E-mail address:iwamura@eng.hokudai.ac.jp (S.Iwamura)

E-mail address:smukai@eng.hokudai.ac.jp (S. R. Mukai)

Fax: +81-11-706-6593 


\section{Sample holder for XRD measurement}

Figure $\mathrm{S} 1$ shows the sample holder used in XRD measurements. The polyimide tape covering the sample prevents air exposure. The gaps between the metal parts are filled with silicon grease.

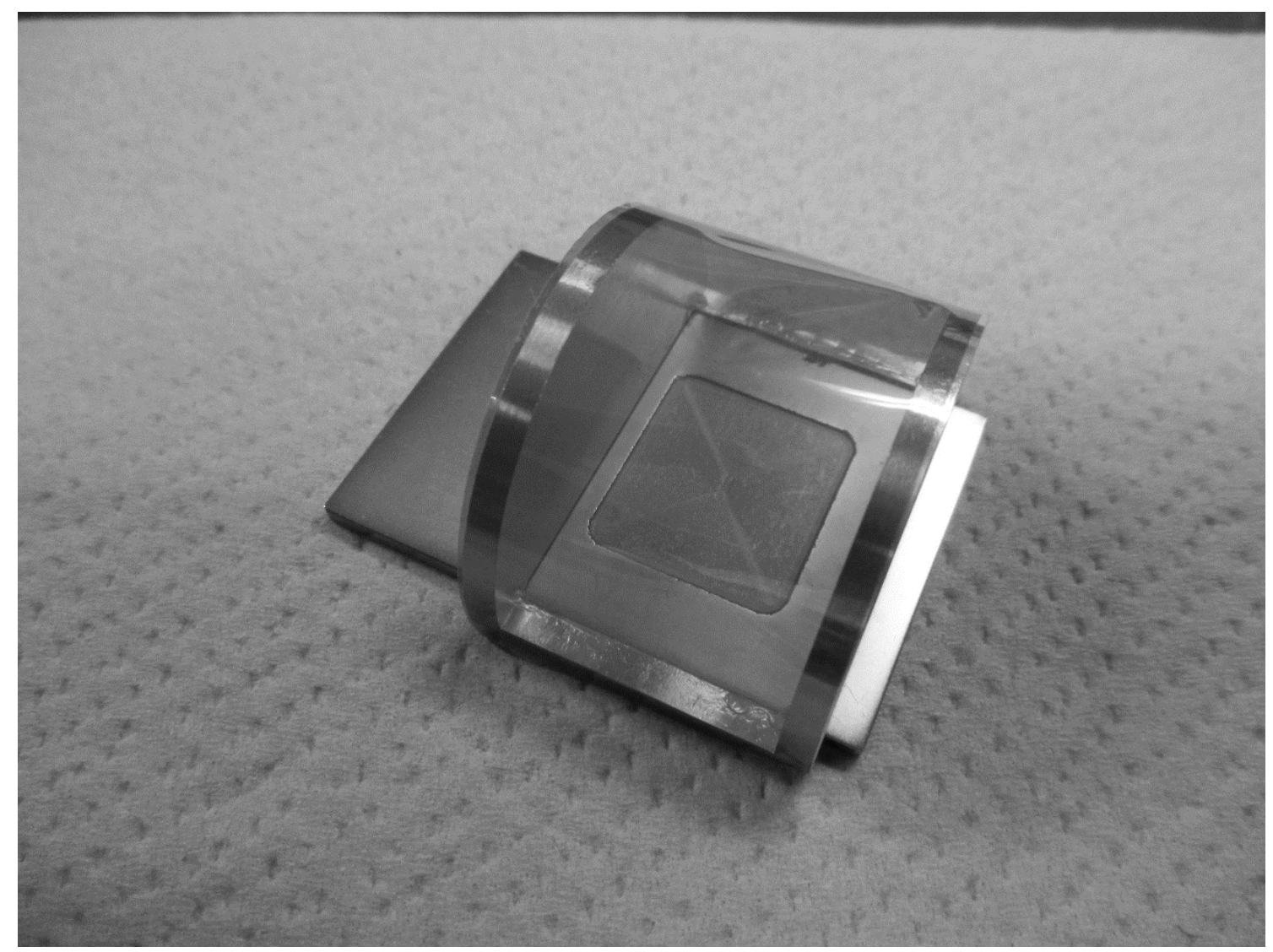

Figure S1 Sample holder used in XRD measurements. 
2. Effect of remaining NMP on porous structure

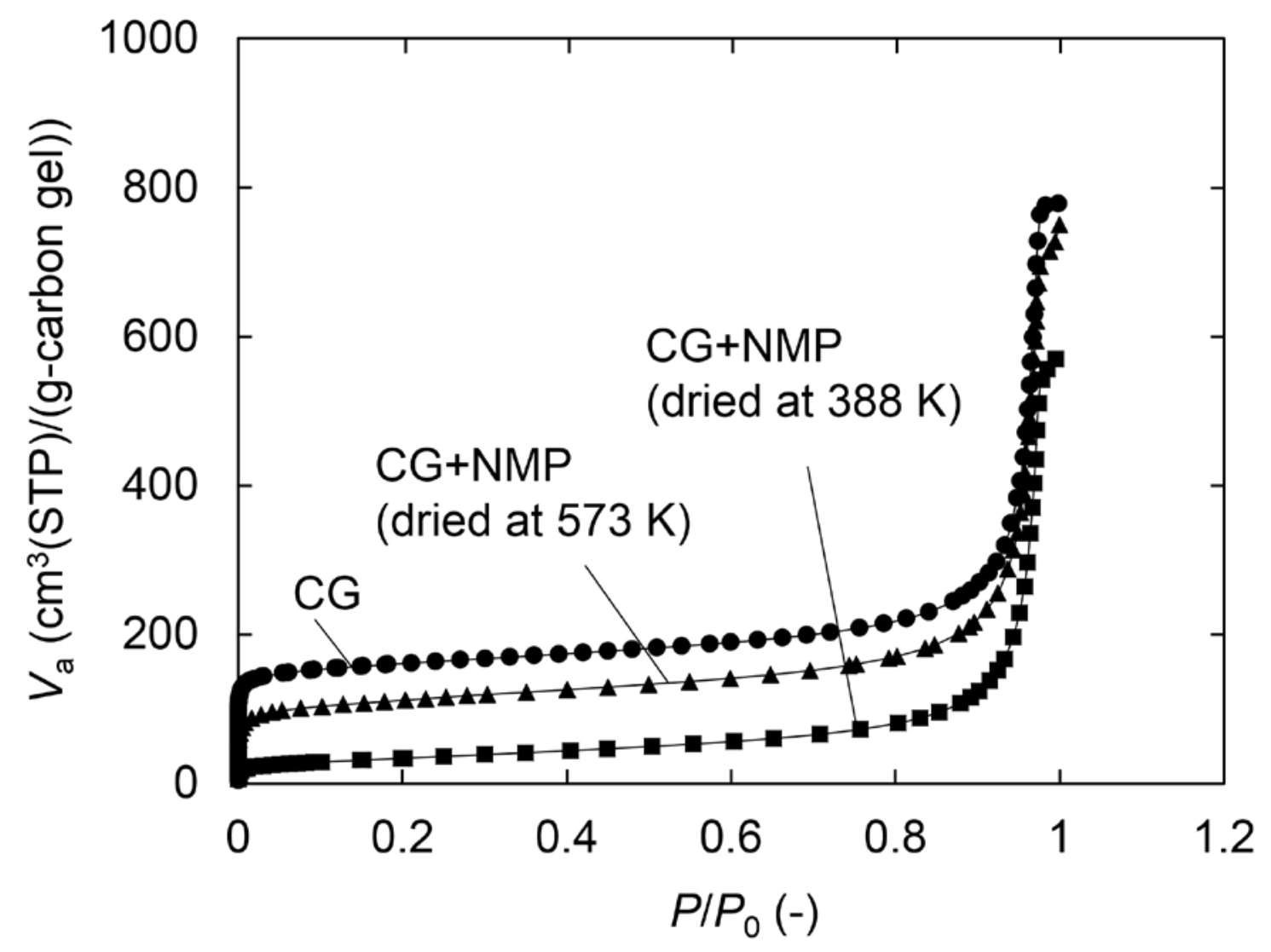

Figure S2 $\mathrm{N}_{2}$ adsorption isotherms at $77 \mathrm{~K}$ of a carbon gel (CG) and carbon gels which were immersed in NMP and dried (CG+NMP). (R/C1000) 
3. Crystal structure of the carbon paper

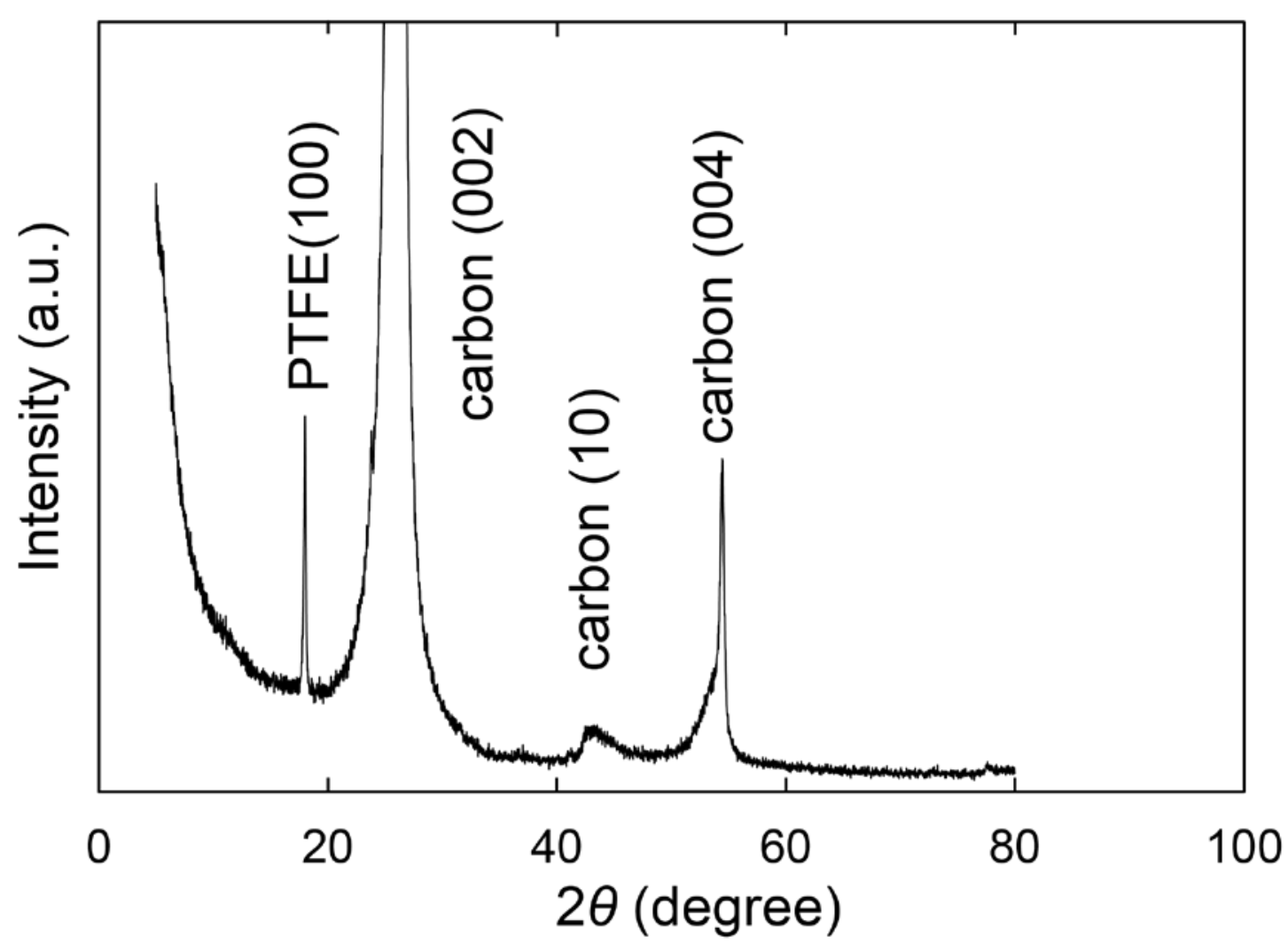

Figure S3 XRD pattern of the carbon paper which is used as a current collector. 


\section{XPS measurements}

Figure S4 and S5 show XPS O1s and C1s spectra, respectively, of a typical carbon-gel cathode (R/C1000) measured prior to and after discharging for 20 hours at $50 \mathrm{~mA} / \mathrm{g}$. The $01 \mathrm{~s}$ spectra can be deconvoluted into 3 peaks. The peak at $532.6 \mathrm{eV}$ is attributed to the oxygen atom in carbonyl groups and hydroxyl groups ${ }^{(1)}$. The peaks at $530.4 \mathrm{eV}$ found in the spectrum of the sample prior to discharging are identified as indium oxide which was used to hold the sample ${ }^{(1,2)}$. The peaks at $536.4 \mathrm{eV}$ found in the spectrum of the sample prior to and after discharging may be shake up peaks ${ }^{(3)}$, which are often considered to be derived from adsorbed $\mathrm{H}_{2} \mathrm{O}$ and/or $\mathrm{O}_{2}{ }^{(4-8)}$. After discharging for 20 hours, the peak at around $530.4 \mathrm{eV}$ enlarged, indicating $\mathrm{Li}_{2} \mathrm{O}_{2}$ deposition ${ }^{(9)}$. The peak corresponding to $\mathrm{Li}_{2} \mathrm{CO}_{3}$ is often observed in the range of 532.1-532.7 eV in previous reports $(9,10)$, where peaks of carbonyl groups or hydroxyl groups are also observed. As carbonyl groups and/or hydroxyl groups exist in the carbon-gel cathode, as shown in the spectra prior to discharging, it is difficult to separate the peaks of byproducts such as $\mathrm{Li}_{2} \mathrm{CO}_{3}$ and carboxylate from the peaks of them. The $\mathrm{C} 1 \mathrm{~s}$ spectra shown in Figure S5 can be deconvoluted into 4 peaks, which correspond to graphitized carbon, $\mathrm{C}-\mathrm{F}$ bond, $\mathrm{C}-\mathrm{O}$ bond and $\mathrm{C}=\mathrm{O}$ bond 284.6 at $\mathrm{eV}, 292.5 \mathrm{eV}, 285.7 \mathrm{eV}$ and $289.0 \mathrm{eV}$, respectively. The intensity of the peak of graphitized carbon clearly decreased with discharging. This would be because the amount of carbon in a detectable depth decreases with the thickness of deposits. C-F bonds are identified only in the cathode after discharging for 20 hours. They are derived from $\mathrm{CF}_{3} \mathrm{SO}_{3} \mathrm{Li}$ used as a salt in the electrolyte. The residual of TEGDME in the electrolyte also increases the intensity of $\mathrm{C}-\mathrm{O}$ bonds. The intensity of $\mathrm{C}=\mathrm{O}$ bonds hardly changed by discharging. Considering the decrease of the amount of carbon near the surface, the amount of $\mathrm{C}=\mathrm{O}$ bonds would increase. This result suggests the presence of byproducts such as $\mathrm{Li}_{2} \mathrm{CO}_{3}$ and carboxylate containing species. The byproducts suggested from these XPS results are consistent with the previous report in the battery system using $\mathrm{CF}_{3} \mathrm{SO}_{3} \mathrm{Li} / \mathrm{TEGDME}$ as the electrolyte ${ }^{(11)}$. 

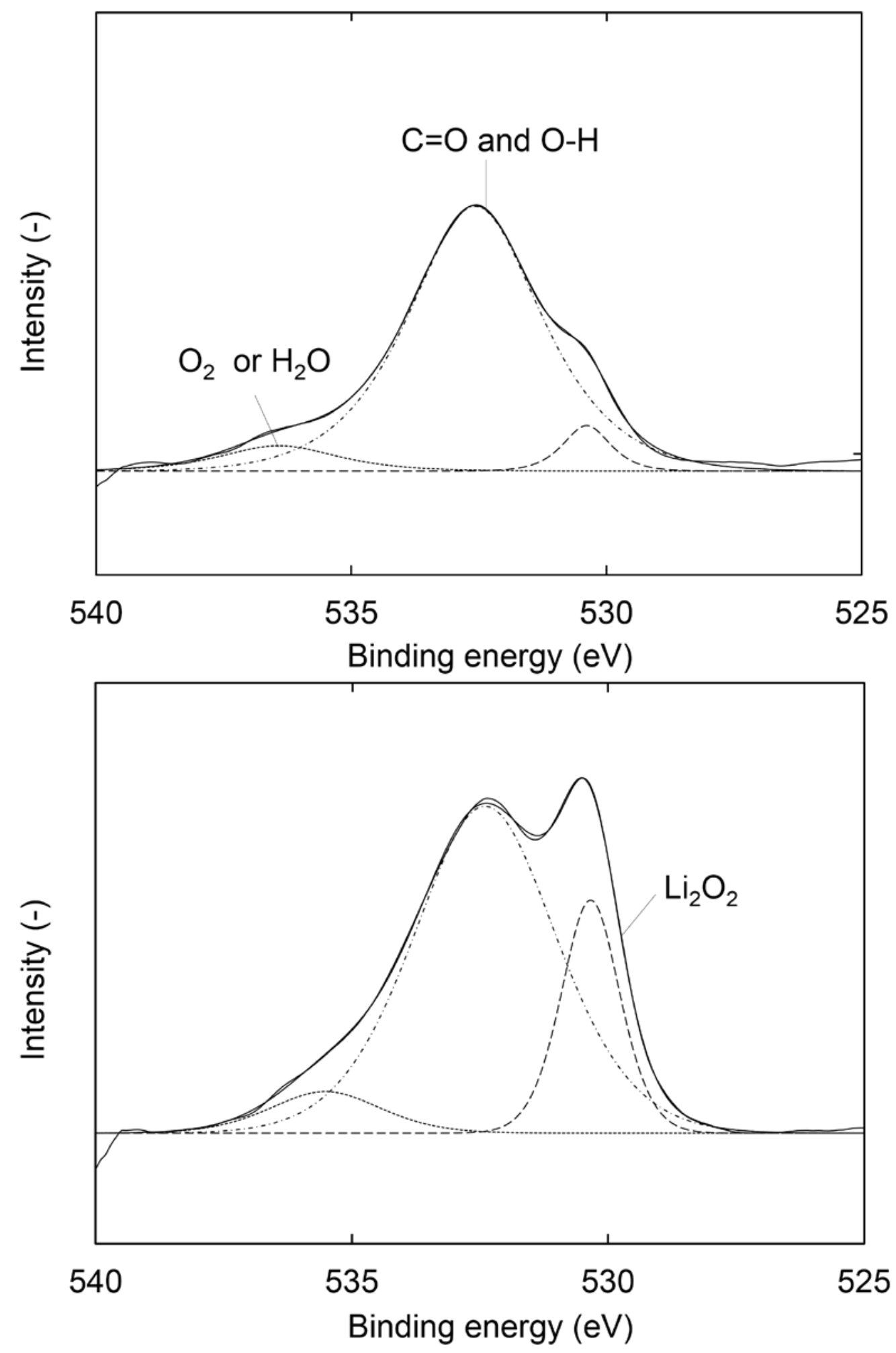

Figure S4 XPS O1s spectra of a typical carbon-gel cathode (R/C1000) (top figure) prior to and (bottom figure) after discharging for 20 hours. 

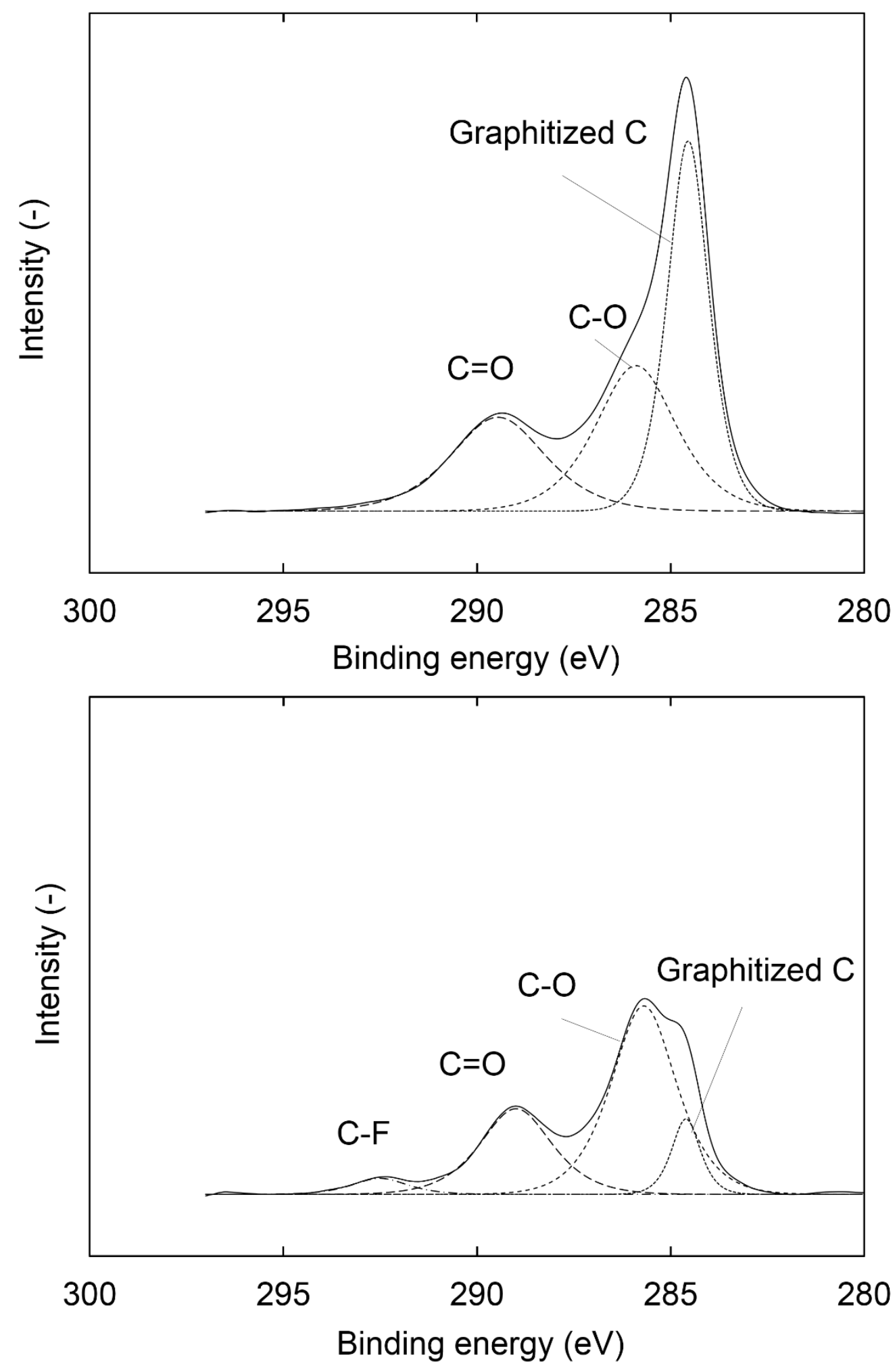

Figure S5 XPS C1s spectra of a typical carbon-gel cathode (R/C1000) (top figure) prior to and (bottom figure) after discharging for 20 hours. 


\section{Reference}

1. J. H. Zhou, Z. J. Sui, J. Zhu, P. Li, C. De, Y. C. Dai and W. K. Yuan, Carbon, 45, 785 (2007).

2. Z. Xu, T. Kosugi, K. Gamo and S. Namba, J.Vac. Sci. Technol. B, 7, 1959 (1989).

3. H. Darmstadt, C. Roy and S. Kaliaguine, Carbon, 32, 1399 (1994).

4. $\quad$ A. Proctor and P. M. A. Sherwood, Carbon, 21, 53 (1983).

5. C. Kozlowski and P. M. A. Sherwood, Carbon, 24, 357 (1986).

6. S. Biniak, G. Szymanski, J. Siedlewski and A. Swiatkowski, Carbon, 35, 1799 (1997).

7. P. V. Lakshminarayanan, H. Toghiani and C. U. Pittman, Carbon, 42, 2433 (2004).

8. J. L. Figueiredo, M. F. R. Pereira, M. M. A. Freitas and J. J. M. Orfao, Carbon, 37, 1379 (1999).

9. D. Chalasani and B. L. Lucht, Ecs Electrochem. Lett., 1, A38 (2012).

10. K. P. C. Yao, D. G. Kwabi, R. A. Quinlan, A. N. Mansour, A. Grimaud, Y. L. Lee, Y. C. Lu and Y. Shao-Horn, J. Electrochem. Soc., 160, A824 (2013).

11. E. Nasybulin, W. Xu, M. H. Engelhard, Z. M. Nie, S. D. Burton, L. Cosimbescu, M.

E. Gross and J. G. Zhang, J. Phys. Chem. C, 117, 2635 (2013). 